\title{
Synthesis and characterization of maghemite nanopowders by chemical precipitation method
}

\author{
Mousa Nazari • Nahid Ghasemi · Heydar Maddah • \\ Mohammad Mousavi Motlagh
}

Received: 26 January 2014/ Accepted: 15 March 2014/Published online: 3 April 2014

(c) The Author(s) 2014. This article is published with open access at Springerlink.com

\begin{abstract}
In this study, nanoparticles of maghemite $\left(\gamma-\mathrm{Fe}_{2} \mathrm{O}_{3}\right)$ with a mean particle size of $9 \mathrm{~nm}$ have been prepared by chemical precipitation method through one step. According to the high-resolution X-ray diffraction result, the as-synthesized iron oxide nanoparticles were $\gamma-\mathrm{Fe}_{2} \mathrm{O}_{3}$. The particle size of the maghemite nanoparticles was below $20 \mathrm{~nm}$ confirmed by transmission electron microscopy image. The particle shape was almost a sphere confirmed by transmission electron microscope.
\end{abstract}

Keywords Iron oxide nanoparticles - Maghemite · Chemical precipitation

\section{Background}

Iron oxides exist in different forms in nature, magnetite, maghemite, and hematite [1] Maghemite is ferrimagnetic at room temperature but maghemite nanoparticles smaller than $10 \mathrm{~nm}$ are superparamagnetic at room temperature, maghemite is unstable at high temperatures, and loses its susceptibility with time $[2,3]$.

M. Nazari · M. M. Motlagh

Department of Engineering, Mosem Research Center,

Emam Hossein University, Tehran, Iran

N. Ghasemi $(\bowtie) \cdot H$. Maddah

Department of Chemistry, Sciences Faculty, Arak Branch,

Islamic Azad University, Arāk, Iran

e-mail: n-ghasemi@iau-arak.ac.ir

N. Ghasemi

Process Systems Engineering Center (PROSPECT), Faculty of Chemical Engineering, Universiti Teknologi Malaysia (UTM), P.O. Box 81310, Skudai 81310, Johor, Malaysia
Among the researchers working in the field of nanotechnology, magnetic nanoparticles have attracted intense experimental activities because of their potential applications in a numerous different industries such as storage of information [4], ferrofluid [5], audio and video recording [6], bioprocess [7] gas sensor [8-13], refrigeration systems [14], information storage [15], medical applications [16], magnetic resonance imaging [17], catalyst [18, 19], magnetooptic [20], and removal of heavy metals [38, 39].

We have various chemistry methods for iron oxide nanoparticles preparation, including gas phase methods (reduction, hydrolysis, disproportionation, oxidation, or other reactions to precipitate solid products from the gas phase), that depend on thermal decomposition [21], liquid phase methods, two-phase methods, sol-gel methods, highpressure hydrothermal methods [22], various methods have been reported for the synthesis of maghemite nanoparticles, such as co-precipitation [23-25], sol-gel synthesis [26-28], micro emulsion [29], flow injection synthesis [30], hydrothermal synthesis [31, 32], flame spray pyrolysis [33], decomposition of organic precursors at high temperatures, and the oxidation of magnetite nanoparticles [31, 34].

Among various chemical methods for synthesis of different types of metal oxides, co-precipitation process has several advantages over other methods including, good homogeneity, low cost, high purity of product and not requiring organic solvents and heat treatment. Recently, co-precipitation method has been developed for preparation of magnetite nanoparticles using metallorganic precursors. In this paper, we report the synthesis and characterization of the $\gamma-\mathrm{Fe}_{2} \mathrm{O}_{3}$ nanoparticles by a chemical co-precipitation technique of ferric and ferrous ions. In this method, unlike previous methods of producing maghemite nanoparticles, we do not need expensive equipments, organic solvents and Hydrochloric acid which 
is a corrosive substance in the industry and create corrosion in equipment. Also, production time, compared with the previous method is faster and has the ability to produce on an industrial scale.

\section{Methods}

To prepare Iron oxide nanoparticles, especially maghemite $\left(\gamma-\mathrm{Fe}_{2} \mathrm{O}_{3}\right)$, ferric chloride $\left(\mathrm{FeCl}_{3}, 99 \%\right)$, ferrous chloride tetra hydrate $\left(\mathrm{FeCl}_{2} \cdot 4 \mathrm{H}_{2} \mathrm{O}, 98 \%\right)$, hydrochloric acid $(\mathrm{HCl}$, $37 \%)$, ammonium hydroxide $\left(\mathrm{NH}_{4} \mathrm{OH}, 25-30 \%\right.$ of ammonia), de-ionized water, and ethanol $\left(\mathrm{CH}_{3} \mathrm{CH}_{2} \mathrm{OH}\right.$, $99.93 \%$ ) were used in the experiments. All the reagents used were of analytical grade. The synthesis was as follows:

$\mathrm{FeCl}_{3}$ and $\mathrm{FeCl}_{2} \cdot 4 \mathrm{H}_{2} \mathrm{O}$ were dissolved in a $2 \mathrm{M}$ hydrochloric acid to form a solution with the concentration of $1 \mathrm{M}$ for $\mathrm{FeCl}_{3}$ and $2 \mathrm{M}$ for $\mathrm{FeCl}_{2} \cdot 4 \mathrm{H}_{2} \mathrm{O}$. The $\mathrm{NH}_{3} \cdot \mathrm{H}_{2} \mathrm{O}$ solution $(0.8 \mathrm{M})$ was dropped to this solution with vigorous stirring at room temperature for $80 \mathrm{~min}$. The final $\mathrm{pH}$ was 8.7 .

$\mathrm{FeCl}_{3}$ and $\mathrm{FeCl}_{2} \cdot 4 \mathrm{H}_{2} \mathrm{O}$ were dissolved in a de-ionized water to form a solution with the concentration of $1 \mathrm{M}$ for $\mathrm{FeCl}_{3}$ and $2 \mathrm{M}$ for $\mathrm{FeCl}_{2} \cdot 4 \mathrm{H}_{2} \mathrm{O}$. The $\mathrm{NH}_{3} \cdot \mathrm{H}_{2} \mathrm{O}$ solution $(0.8 \mathrm{M})$ was dropped to this solution with vigorous stirring at room temperature for $40 \mathrm{~min}$. The final $\mathrm{pH}$ was 8.3.

The brown precipitate was then collected by filtration and rinsed three times with deionized water and ethanol. Finally, the washed precipitate was dried at room temperature.
The crystallographic structure of the as-synthesized iron oxide nanoparticles was characterized by high-resolution XRD analysis (Philips, $\mathrm{X}$, pert-MPD) using $\mathrm{Cu} \mathrm{Ka}$ $(\lambda=1.54 \AA$ ) radiation and the crystallite size was estimated using Scherrer's formula.

IR spectra were recorded on a Bruker tensor 27 FTIR spectrometer with RTDLATGS detector, in the range of $400-4,000 \mathrm{~cm}^{-1}$ with a spectral resolution of $4 \mathrm{~cm}^{-1}$ in transmittance mode. The surface morphology of the powders was observed by the TEM (CM-120 PW6031/10). The magnetic properties of the as-synthesized nanopowders were analyzed by a vibrating sample magnetometer (VSM), in the Development Center of Kashan University (Kashan, Iran).

\section{Results and discussion}

The crystalline structure of the nanoparticles was characterized by X-ray diffraction (XRD, PHILIPS, X'pert-MPD system) using $\mathrm{Cu} \mathrm{K} \alpha\left(\lambda=1.54 \mathrm{~A}^{\circ}\right)$ radiation and the crystallite size was estimated using Scherrer's formula. The results of analysis material by X-ray diffraction are shown in Fig. 1, which can be indexed as the primitive cubic system by comparison with data from $\gamma-\mathrm{Fe}_{2} \mathrm{O}_{3}$ (JCPDS No. 39-1346) [28]. The diffraction peaks at $2 \theta=18.30^{\circ}$, $30.20^{\circ}, 35.45^{\circ}, 43.32^{\circ}, 53.81^{\circ}, 57.22^{\circ}, 62.98^{\circ}, 74.54^{\circ}$, correspond to (1 111$),\left(\begin{array}{lll}2 & 2 & 0\end{array}\right),\left(\begin{array}{lll}3 & 1 & 1\end{array}\right),\left(\begin{array}{lll}4 & 0 & 0\end{array}\right),\left(\begin{array}{lll}4 & 2 & 2\end{array}\right)$, (5 11 1), (4 40 ) and (5 33 3), respectively. No impurity peak indicates that the product is pure. According to the
Fig. 1 X-ray diffraction patterns of $\gamma$-Fe2O3 nanoparticles by chemical precipitation method at room temperature

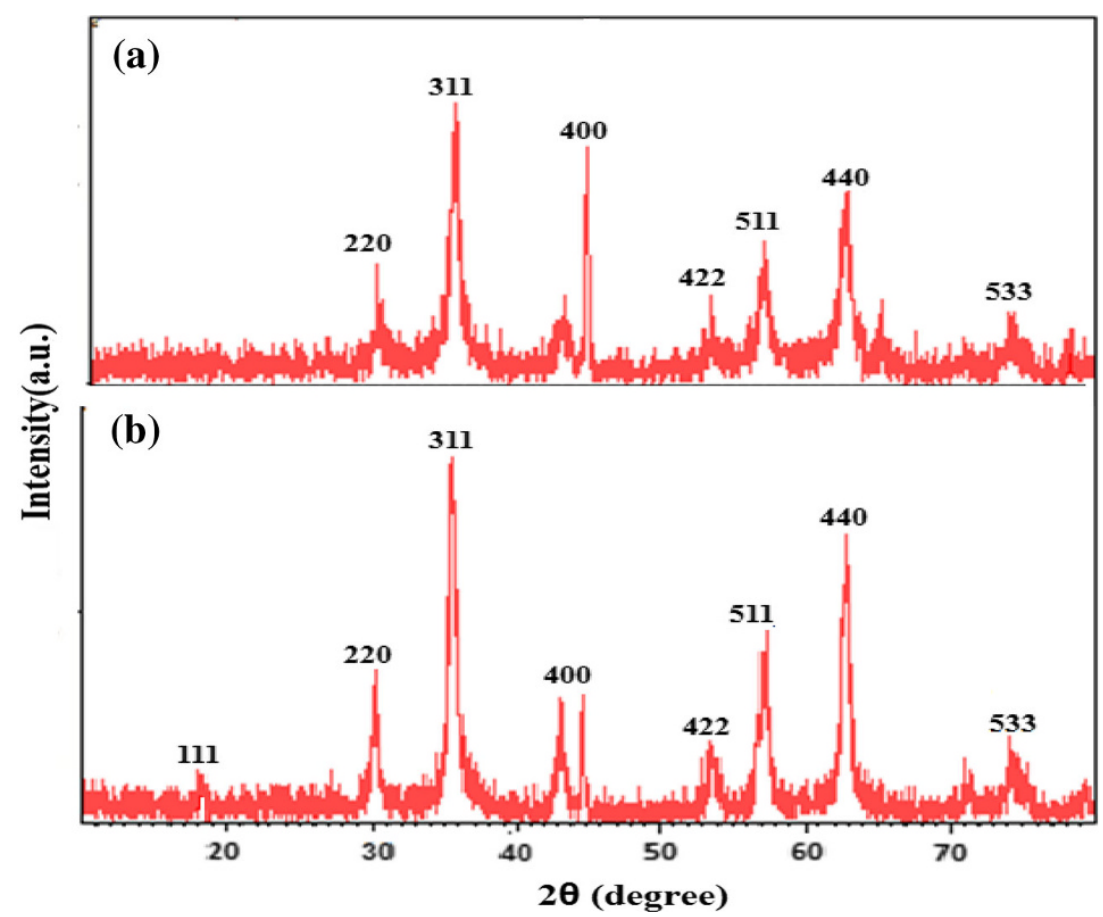


Fig. 2 FT-infrared spectra of $\gamma-\mathrm{Fe}_{2} \mathrm{O}_{3}$ nanoparticles performed by $200 \mathrm{mg} \mathrm{KBr}$

Fig. 3 TEM images of $\gamma-\mathrm{Fe}_{2} \mathrm{O}_{3}$ nanoparticles for a the sample that $2 \mathrm{M}$ hydrochloric acid was used in process and $\mathbf{b}$ the sample that deionized water was used in process
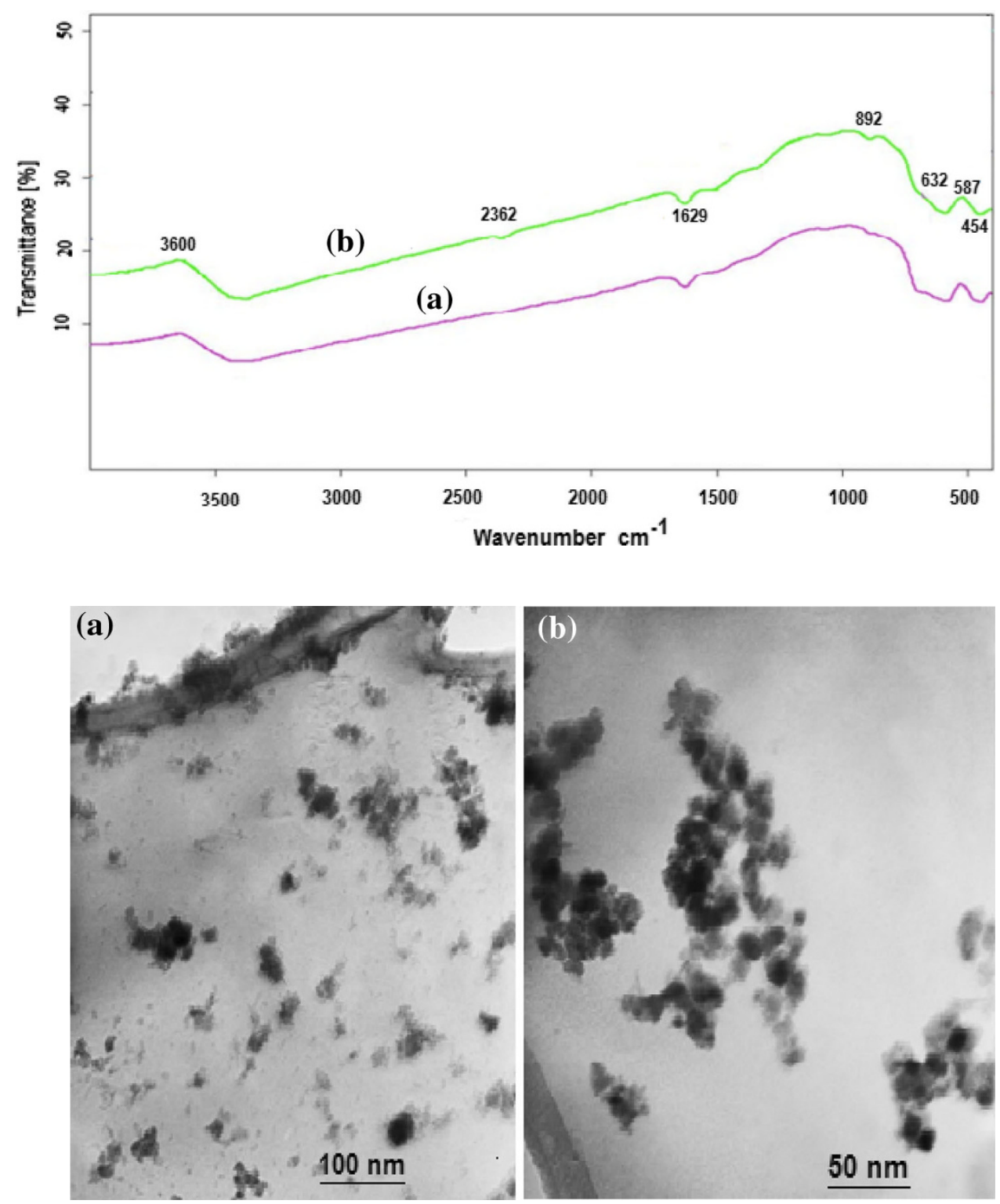

Scherrer's equation, the average crystallite size of the product was calculated to be about $8-12 \mathrm{~nm}$.

Figure 2 shows the FTIR spectrum of the sample, the absorption peak at $587 \mathrm{~cm}^{-1}$ identified vibration of $\gamma \mathrm{Fe}-\mathrm{O}$ $[35,36]$, and the other peaks at pure maghemite are 454 , $632,795,892 \mathrm{~cm}^{-1}$. The two absorption peaks at 3,170 and $3,408 \mathrm{~cm}^{-1}$ arising from the $\mathrm{O}-\mathrm{H}$ group stretching band and the absorption peak at $1,629 \mathrm{~cm}^{-1}$ correspond to hydroxyl group $(\mathrm{O}-\mathrm{H})$ of water [34]. There is a tiny dip in the spectra at $2,362 \mathrm{~cm}^{-1}$ due to the presence of atmospheric $\mathrm{CO}_{2}$ [35]. The FTIR spectra show no impurities such as chloride and ammonium groups in the sample.

The size and shape of maghemite nanoparticles were investigated using TEM device. Figure 3 shows the TEM images and distribution curve of maghemite nanoparticles for (a) the sample that $2 \mathrm{M}$ hydrochloric acid was used in process and (b) is for the sample that deionized water was used in process. Figure 4 shows the distribution of iron oxide nanoparticles for the sample (a) and sample (b). The results show that the size of nanoparticles is decreased, and their homogeneity is increased using deionized water in process in comparison with the process that $2 \mathrm{M}$ hydrochloric acid was used. The shape of nanoparticles was spherical and the average size of them was $8 \mathrm{~nm}$ for first sample and $12 \mathrm{~nm}$ for second sample.

Figure 5 shows a magnetization hysteresis loop for the prepared $\gamma-\mathrm{Fe}_{2} \mathrm{O}_{3}$ nanoparticle powder at room temperature. The values of saturation magnetization and coercivity 
(a)

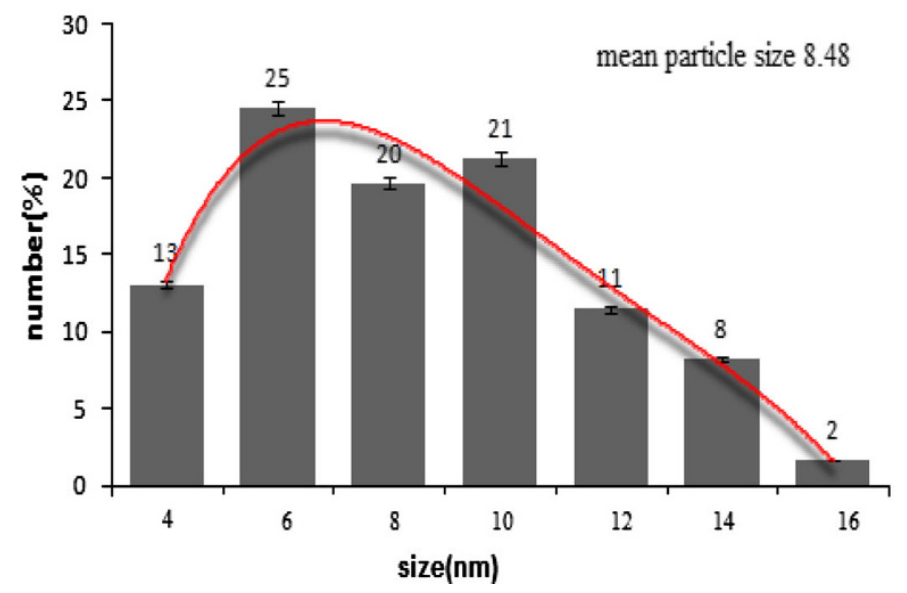

(b)

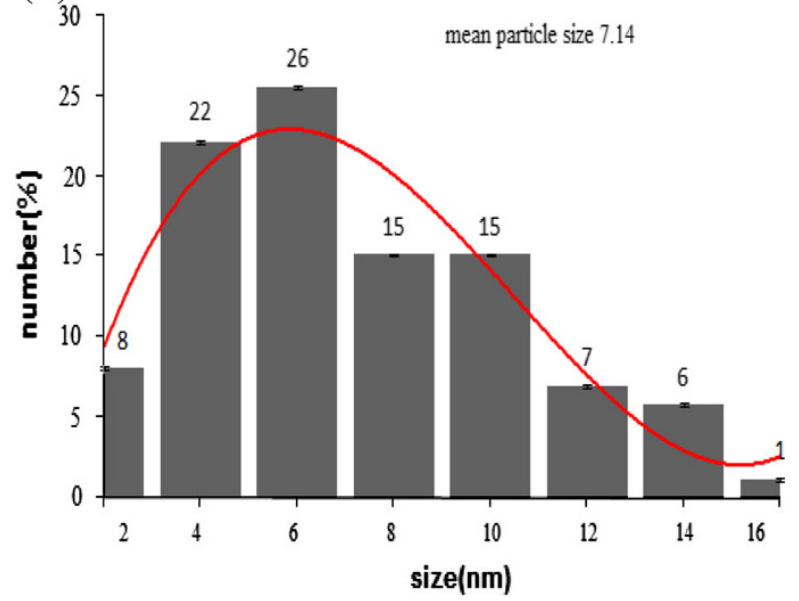

Fig. 4 Particle size distributions measured from TEM images for $\mathbf{a}$ the sample that $2 \mathrm{M}$ hydrochloric acid was used in process and $\mathbf{b}$ the sample that deionized water was used in process

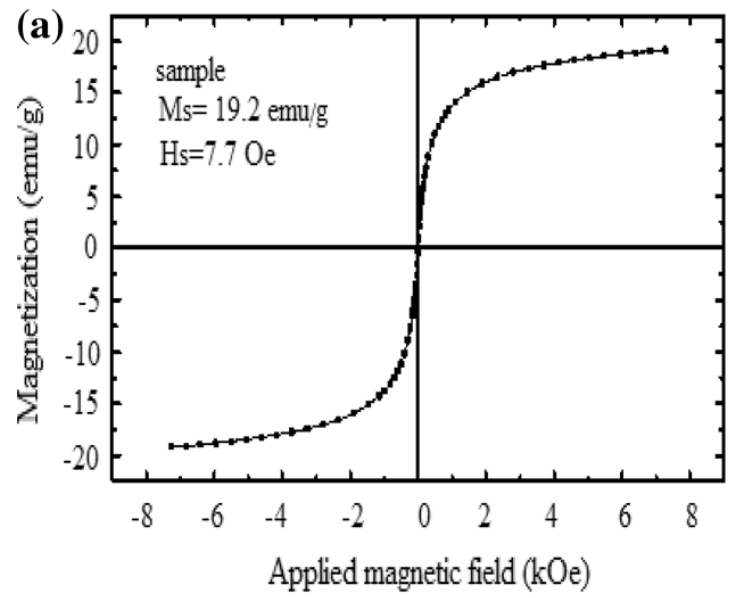

Fig. 5 Magnetization hysteresis loop for as-prepared powder

were $M_{\mathrm{s}}=19.2 \mathrm{emu} \mathrm{g}{ }^{-1}, H_{\mathrm{s}}=7.7$ Oe for first sample and were $M_{\mathrm{s}}=50 \mathrm{emu} \mathrm{g}^{-1}, H_{\mathrm{s}}=50 \mathrm{Oe}$ for second sample. By increasing saturation magnetization factor, the size of the nanoparticle is decreased [37].

\section{Conclusions}

In summary, $\gamma-\mathrm{Fe}_{2} \mathrm{O}_{3}$ nanoparticles have been prepared by chemical precipitation method at room temperature. The procedure in the present study offers very important advantageous features for preparation of maghemite nanoparticles. The synthetic process is economical, able to control the size of nanoparticles and production scale up and do not need heating stage and complex equipment. The XRD patterns indicated that as-synthesized iron oxide nanoparticles were maghemite. According to

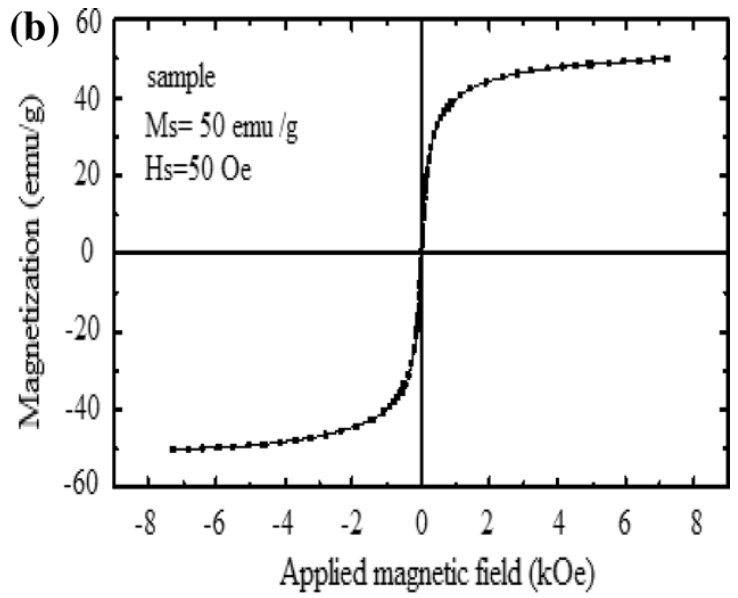

the TEM image, the particle size was around $9 \mathrm{~nm}$, and particle shape was almost a sphere. The saturation magnetization of the iron oxide nanopowders was $50 \mathrm{emu}^{-1}$.

Conflict of interest The authors declare that they have no competing interests.

Author contribution MS proposed the study, carried out the experiments, performed the statistical analysis, revised, drafted manuscript, and financially supported the project. NG helped to revised, draft the manuscript. HM carried out the experiments and to draft the manuscript and MMM carried out the experiments and to draft the manuscript. All authors read and approved the final manuscript.

Open Access This article is distributed under the terms of the Creative Commons Attribution License which permits any use, distribution, and reproduction in any medium, provided the original author(s) and the source are credited. 


\section{References}

1. Cornell, R.M., Schwertmann, U.: The Iron Oxides: Structure, Properties, Reactions, Occurrences and Uses, 2nd edn. Wiley, Weinheim (2003)

2. Ray, I., Chakraborty, S., Chowdhury, A., Majumdar, S., Prakash, A., Pyare, R., Sen, A.: Room temperature synthesis of $\gamma-\mathrm{Fe}_{2} \mathrm{O}_{3}$ by sonochemical route and its response towards butane. Sens. Actuators B 130, 882-888 (2008)

3. Neuberger, T., Schopf, B., Hofmann, H., Hofmann, M., von Rechenberg, B.: Superparamagnetic nanoparticles for biomedical applications: possibilities and limitations of a new drug delivery system. J. Magn. Magn. Mater. 293(1), 483-496 (2005)

4. Ensling, J., Gütlich, P., Klinger, R., Meisel, W., Jachow, H., Schwab, E.: Magnetic pigments for recording media. Hyperfine Interact. 111(1-4), 143-150 (1998)

5. Büscher, K., Helm, C.A., Gross, C., Glöckl, G., Romanus, E., Weitschies, W.: Langmuir 20, 2435 (2004)

6. Kiemle, P., Wiese, J., Buxbaum, G.: Process for the production of iron oxides epitaxially coated with cobalt, the coated oxides and their cue. US Patent No. 652214

7. Pope, N.M., Alsop, R.C., Chang, Y.A., Smith, A.K.: Evaluation of magnetic alginate beads as a solid support for positive selection of CD34 + cells. J. Biomed. Mater. Res. 28, 449-457 (1994)

8. Jing, Z., Wang, Y., Wu, S.: Sens. Actuator B 113, 177 (2006)

9. Liao, M., Chen, D.: Preparation and characterization of a novel magnetic nano-adsorbent. J. Mater. Chem. 12, 3654-3659 (2002)

10. Jing, Z., Wu, S.: Synthesis, characterization and gas sensing properties of undoped and Co-doped- $\mathrm{Fe}_{2} \mathrm{O}_{3}$-based gas sensors. Mater. Lett. 60, 952-956 (2006)

11. Liu, Y., Zhu, W., Tan, O.K., Shen, Y.: Structural and gas sensing properties of ultrafine $\mathrm{Fe}_{2} \mathrm{O}_{3}$ prepared by plasma enhanced chemical vapor deposition. Mater. Sci. Eng. B 47, 171-176 (1997)

12. Lim, I.S., Jang, G.E., Kim, C.K., Yoon, D.H.: Fabrication and gas sensing characteristics of pure and Pt-doped- $-\mathrm{Fe}_{2} \mathrm{O}_{3}$ thin film. Sens. Actuators B 77, 215-220 (2001)

13. Wang, J., Tong, M., Wang, X., Ma, Y., Liu, D., Wu, J., Gao, D., $\mathrm{Du}, \mathrm{G}$.: Preparation of $\mathrm{H}_{2}$ and LPG gas sensor. Sens. Actuators B 84, 95-97 (2002)

14. Mørup, S., Tronc, E.: Superparamagnetic relaxation of weakly interacting particles. Phys. Rev. Lett. 72, 3278 (1994)

15. Sinha, A., Chakraborty, J., Rao, V.: Process for preparing nanosized acicular magnetic maghemite phase iron oxide particles. European Patent EP1559118

16. Nagano, H., Machida, Y., Iwata, M., Imada, T., Noguchi, Y., Matsumoto, A., Nagai, T.: Preparation of magnetic granules containing bleomycin and its evaluation using model esophageal cancer. Int. J. Pharm. 147, 119-125 (1997)

17. Billotey, C., Wilhelm, C., Devaud, M., Bacrij, C., Bittoun, J., Gazeau, F.: Medical cell internalization of anionic maghemite nanoparticles: quantitative effect on magnetic resonance imaging. Magn. Reson. Med. 49, 646-654 (2003)

18. Rostovshchikova, T.N., Kiseleva, O.I., Smirnov, V.V., Maksimov, Y.V., Suzdalev, I.P., Prusakov, V.E., Tsodikov, M.V., Ikorskiid, V.N.: Catalytic conversions of chloroolefines over iron oxide nanoparticles 3. Electronic and magnetic properties of $\gamma-\mathrm{Fe}_{2} \mathrm{O}_{3}$ nanoparticles immobilized on different silicas. Russ. Chem. Bull. Int. 55, 1768-1774 (2006)

19. Dutta, A.K., Maji, S.K., Adhikary, B.: $\gamma-\mathrm{Fe}_{2} \mathrm{O}_{3}$ nanoparticles: an easily recoverable effective photo-catalyst for the degradation of rose bengal and methylene blue dyes in the waste-water treatment plant. Mater. Res. Bull. 49, 28-34 (2014)

20. Ortega, D., Garitaonandia, J.S., Barrera-Solano, C., Ramírezdel-Solar, M., Blanco, E., Domínguez, M.: $\gamma-\mathrm{Fe}_{2} \mathrm{O}_{3} / \mathrm{SiO}_{2}$ nanocomposites for magneto-optical applications: nanostructural and magnetic properties. J. Non-Cryst. Solids 352, 2801-2810 (2006)

21. Pierson, H.O.: Handbook of Chemical Vapor Deposition: Principles, Technology, and Applications. William Andrew Inc (1999)

22. Teja, A.S., Koh, P.Y.: Synthesis: properties, and applications of magnetic iron oxide nanoparticles. Prog. Cryst. Growth Charact. Mater. 55, 22-45 (2009)

23. Lee, S.J., Jeong, J.R., Shin, S.C., Kim, J.C., Kim, J.D.: Impedance spectra of field-aligned CF02 needle-shape powders. J. Magn. Magn. Mater. 282, 147 (2004)

24. Darezereshki, E.: Synthesis of maghemite $\left(\gamma-\mathrm{Fe}_{2} \mathrm{O}_{3}\right)$ nanoparticles by wet chemical method at room temperature. Mater. Lett. 64, 1471-1472 (2010)

25. Layek, S., Pandey, A., Pandey, A., Verma, H.C.: Synthesis of $\gamma-\mathrm{Fe}_{2} \mathrm{O}_{3}$ nanoparticles with crystallographic and magnetic texture. Int. J. Eng. Sci. Technol. 2(8), 33-39 (2010)

26. da Costa, G.M., De Grave, E., de Bakker, P.M.A., Vandenberghe, R.E.: Synthesis and characterization of some iron oxides by solgel method. J. Solid State Chem. 113, 405-412 (1994)

27. Cui, H., Ren, W.: Low temperature and size controlled synthesis of monodispersed $\gamma-\mathrm{Fe}_{2} \mathrm{O}_{3}$ nanoparticles by an epoxide assisted sol-gel route. J. Sol Gel Sci. Technol. 47, 81-84 (2008)

28. Cui, H., Liu, Y., Ren, W.: Structure switch between a-Fe $\mathrm{O}_{2} \mathrm{O}_{3}$, $\gamma-\mathrm{Fe}_{2} \mathrm{O}_{3}$ and $\mathrm{Fe}_{3} \mathrm{O}_{4}$ during the large scale and low temperature sol-gel synthesis of nearly monodispersed iron oxide nanoparticles. Adv. Powder Technol. 24, 93-97 (2013)

29. Chin, A.B., Yaacob, I.I.: Synthesis and characterization of magnetic iron oxide nanoparticles via w/o microemulsion and Massart's procedure. J. Mater. Process. Technol. 191, 235-237 (2007)

30. Alvarez, G.S., Muhammed, M., Zagorodni, A.A.: Novel flow injection synthesis of iron oxide nanoparticles with narrow size distribution. Chem. Eng. Sci. 61, 4625-4633 (2006)

31. Liu, T., Guo, L., Tao, Y.: Synthesis and interfacial structure of nanoparticles $\gamma-\mathrm{Fe}_{2} \mathrm{O}_{3}$ coated with surfactant DBS and CTAB. Nanostruct. Mater. 11, 487-492 (1999)

32. Islam, M.S., Kurawaki, J., Kusumoto, Y., Abdulla-Al-Mamuna, M., Bin Mukhlish, M.Z.: Hydrothermal novel synthesis of neckstructured hyperthermia-suitable magnetic $\left(\mathrm{Fe}_{3} \mathrm{O}_{4}, \gamma-\mathrm{Fe}_{2} \mathrm{O}_{3}\right.$ and $\alpha-\mathrm{Fe}_{2} \mathrm{O}_{3}$ ) nanoparticles. J. Sci. Res. 4(1), 99-107 (2012)

33. Strobel, R., Pratsinis, S.E.: Direct synthesis of maghernite, magnetite and wustite nanoparticles by flame spray pyrolysis. Adv. Powder Tech. 20, 190 (2009)

34. Cao, S.-W., Zhu, Y.-J., Zeng, Y.-P.: Formation of $\gamma$-Fe2O3 hierarchical nanostructures at $500{ }^{\circ} \mathrm{C}$ in a high magnetic field. J. Magn. Magn. Mater. 321, 3057-3060 (2009)

35. Chakrabarti, S., Ganguli, D., Chaudhuri, S.: Optical properties of $\gamma-\mathrm{Fe}_{2} \mathrm{O}_{3}$ nanoparticles dispersed on sol-gol silica spheres. J. Physica. E 24, 333 (2004)

36. Haw, C.Y., Mohamed, F., Chia, C.H., Radiman, S., Zakaria, S., Huang, N.M., Lim, H.N.: Hydrothermal synthesis of magnetite nanoparticles as MRI contrast agents. Ceram. Int. 36(4), 1417-1422 (2010)

37. Lee, Y., Jun, K., Park, J., Potdar, H., Chikate, R.: A simple chemical route for the synthesis of $\gamma-\mathrm{Fe}_{2} \mathrm{O}_{3}$ nano-particles dispersed in organic solvents via an iron-hydroxy oleate precursor. J. Ind. Eng. Chem. 14, 38-44 (2008)

38. Tuutijarvi, T., Vahala, R., Sillanpaa, M., Chen, G.: Maghemite nanoparticles for As $(\mathrm{V})$ removal: desorption characteristics and adsorbent recovery. Environ. Technol. 33(16), 1927-1936 (2012)

39. Akhbarizadeh, R., Shayestefar, M.R., Darezereshk, E.: Competitive removal of metals from wastewater by maghemite nanoparticles: a comparison between simulated wastewater and AMD. Mine. Water Environ. 33, 89-96 (2014) 